\title{
CORRIGENDUM
}

\section{Effect of temperature on the phenology of Chilo partellus (Swinhoe) (Lepidoptera, Crambidae); simulation and visualization of the potential future distribution of C. partellus in Africa under warmer temperatures through the development of life-table parameters - CORRIGENDUM}

\author{
N. Khadioli, Z.E.H. Tonnang, E. Muchugu, G. Ong'amo, \\ T. Achia, I. Kipchirchir, J. Kroschel and B. Le Ru \\ doi:10.1017/S0007485314000601, Published by Cambridge University Press, 17 September 2014.
}

The author apologises for omitting some important information from the Acknowledgements section. This has now been included and the whole section reads as follows:

\section{Acknowledgements}

The first author of this study is a PhD student working under 'Predicting climate-change-induced vulnerability of African agricultural systems to major insect pests through advanced insect phenology modeling, and decision aid development for adaptation planning' project. The authors gratefully acknowledge the financial support provided by the Federal Ministry of Cooperation and Development (BMZ), Germany, and by the CHIESA project (Climate Change Impacts on Ecosystem Services and Food Security in Eastern Africa) funded by the Ministry for Foreign Affairs of Finland. The authors thank the two anonymous referees for their valuable comments and suggestions.

\section{Reference}

Khadioli, N., Tonnang, Z.E.H., Muchugu, E., Ong'amo, G., Achia, T., Kipchirchir, I., Kroschel, J. \& Le Ru, B. (2014) Effect of temperature on the phenology of Chilo partellus (Swinhoe) (Lepidoptera, Crambidae); simulation and visualization of the potential future distribution of C. partellus in Africa under warmer temperatures through the development of life-table parameters. Bulletin of Entomological Research. Published by Cambridge University Press, 17 September 2014. doi:10.1017/S0007485314000601. 